\title{
Enfermedad de células I de Leroy o mucolipidosis tipo II
}

Reporte de un caso

Macri-Colucci, Alberto*, Barba-Calvillo Tania Alejandra**.

\begin{tabular}{|c|c|}
\hline Resumen & Abstract \\
\hline $\begin{array}{l}\text { La enfermedad de células I, de Leroy o mucolipidosis II, } \\
\text { es un raro trastorno autosómico recesivo que produce } \\
\text { un déficit en la enzima GlcNAc-fosfotransferasa alteran- } \\
\text { do el transporte lisosomal y se caracteriza clínicamen- } \\
\text { te por un peso bajo al nacer, malformaciones fisicas, } \\
\text { anomalías esqueléticas, organomegalias, severo retraso } \\
\text { psicomotor y muerte entre los cinco y ocho años de } \\
\text { edad debido a complicaciones cardiacas que se agrava } \\
\text { con enfermedades pulmonares agregadas. Se presenta } \\
\text { el reporte de un caso de un paciente masculino de tres } \\
\text { años diez meses de edad, con manifestaciones clínicas } \\
\text { compatibles con el diagnóstico de enfermedad de célu- } \\
\text { las I de Leroy, diagnóstico que se confirmó por medio de } \\
\text { estudios bioquímicos específicos. LUXMÉDICA, AÑo } 7 \text { NuUM } 21 \\
\text { MAY0-AGosTo } 2012 \text { pp 6I-66. }\end{array}$ & $\begin{array}{l}\text { I-Cell Disease, Mucolipidosis tipe II o Leroy syndrome is } \\
\text { a rare autosomal recessive disorder that cause a deficit } \\
\text { in the GlcNAc-phosphotransferase enzyme altering the } \\
\text { lysosomal transport and is characterized clinically by } \\
\text { low birth weight, physical deformities, skeletal abnor- } \\
\text { malities, organomegaly, severe psychomotor retardation } \\
\text { and death between } 5 \text { and } 8 \text { years of age by cardiac } \\
\text { complications with lung disease aggravated added. A } \\
\text { clinical case report of a male patient of } 3 \text { years } 10 \\
\text { months, with clinical manifestations supported with the } \\
\text { diagnosis of Disease Cells Leroy I, diagnosis is confir- } \\
\text { med by specific biochemical studies. LUXMÉDICA, AÑO } 7 \text { NúM } \\
21 \text { MAYO-AGOSTO } 2012 \text { pp 61-66. }\end{array}$ \\
\hline $\begin{array}{r}\text { Palabras claves: enfermedad de células I, } \\
\text { de Leroy, Mucolipidosis II. }\end{array}$ & $\begin{array}{l}\text { Key words I-Cell Disease, Leroy syndrome, } \\
\text { Mucolipidosis type II. }\end{array}$ \\
\hline
\end{tabular}

\section{Introducción}

La enfermedad de células I, de Leroy o mucolipidosis tipo II fue descrita por Leroy y Demars en 1967, es un raro trastorno autosómico recesivo, que origina ${ }^{1,2}$ un déficit de la enzima UDP-N-acetilglucosamina: enzima lisosomal $\mathrm{N}$-acetilglucosamina-1-fosfotransferasa ${ }^{3}$ (GlcNAc fosfotransferasa) que es esencial para el paso de las hidrola-

* Médico genetista y Jefe de Enseñanza del Centro de Rehabilitación Infantil TELETÓN Aguascalientes, Ags.

** Estudiante del octavo semestre de Medicina de la Universidad Autónoma de Aguascalientes.

Fecha de recibido: 2 abril 2012

Fecha de aceptación: 29 de junio 2012

Correspondencia: Dr Alberto Macri Colucci Centro de Rehabilitación Infantil TELETÓN Avenida Heroico Colegio Militar No. 600, CP 20059 Colonia Ferronales, Aguascalientes, Ags, México Teléfono 01449 9102223. Correo electrónico motitas_88@hotmail.com 
sas lisosomales a través de una manosa-6-fosfato (M6P) ${ }^{4}$, este proceso es llevado a cabo en el aparato de Golgi. Como consecuencia, la enzima deficiente en manosa-1-fosfato retiene su actividad hidrolítica pero es incapaz de acceder apropiadamente al lisosoma. Por consiguiente, la reducción en el contenido de enzimas lisosomales en la célula lleva al fracaso en la degradación de las macromoléculas, mientras que hay un exceso de la actividad de la enzima lisosomal en el fluido extracelular ${ }^{5}$, mientras que en el interior de los fibroblastos, los niveles de la enzima se reducen considerablemente ${ }^{6}$. Mucolipidosis II es un trastorno poco común, aunque su prevalencia exacta se desconoce. Se estima que ocurre en aproximadamente uno de cada 100.000 a 400.000 recién nacidos vivos en todo el mundo7. La muerte suele ser a los 5-8 años, por insuficiencia cardíaca progresiva y/o síntomas pulmonares recurrentes ${ }^{1}$.

\section{Presentación del caso}

Se trata de paciente masculino de tres años y diez meses de edad, producto de primer embarazo, obtenido por cesárea a los ocho meses de gestación, cirugía indicada por oligohidramnios. El peso al nacer fue de 2100 gramos y tuvo una talla de $45 \mathrm{~cm}$, con un Apgar de 9. Cursó con ictericia multifactorial manejada con baños de sol. Madre de 28 años al nacimiento, gesta 1, cesáreas 1, abortos 0, no hay antecedentes ni consanguinidad.

Signos vitales: frecuencia cardiaca: $60 \times$ min, frecuencia respiratoria: $20 \times$ min, presión arterial (T/A): 100/70 mm de $\mathrm{Hg}$, Temperatura: $36.1^{\circ} \mathrm{C}$. A la exploración física se aprecia retardo psicomotor, talla baja, pabellones auriculares de implantación baja, facies tosca, cejas pobladas, epicanto, hipertelorismo, puente nasal deprimido, narinas antevertidas, filtrum largo, hiperplasia gingival, micrognatia, cuello corto, tórax con teletelia, mano en garra, hernia umbilical, hepatomegalia, lordosis.

\section{Evaluación multidisciplinaria:}

Nutrición encuentra relaciones: talla - edad: percentil talla baja, años peso/talla: porcentaje estándar de peso: 92\% e Índice de masa corporal: $16.6 / \mathrm{m}^{2}$ superficie corporal. Según los datos antropométricos, su peso ideal para su talla sería de $10 \mathrm{~kg}$ por lo que se inicia guía nutricional de tipo normo energética.

Ortopedia encuentra cifosis postural, manos anchas y cortas así como sus pies. Espasticidad grado 2 en miembros inferiores. Radiografía antero posterior de pelvis que muestran caderas luxadas con incongruencia en líneas de Shenton y Calvé. Índice acetabular derecho de $20^{\circ}$ izquierdo $40^{\circ}$. Radiografía antero posterior de tórax con arcos costales completos, pero con aumento en su densidad. Radiografía antero posterior de ambas manos donde se aprecian huesos cortos y anchos.

En la evaluación por médico rehabilitador, describe un tono aumentado en las cuatro extremidades, reflejos de estiramiento muscular aumentados, clonus bilateral, control de cuello adecuado, sí hay cambios de decúbito pero con un control 
de tronco deficiente prescribiéndose terapia pulmonar, mecanoterapia, tina remolino, terapia ocupacional, terapias en el Centro de Estimulación Múltiple Sensorial (CEMS), atención psicológica y atención familiar.

Neurología reporta un electroencefalograma con epilepsia. En la evaluación cardiológica reporta sin alteraciones cardiacas. Odontopediatría reporta dentición decidua incompleta, incisivos centrales y laterales superiores sin erupción completa, en la arca inferior no presenta ningún órgano dentario. Gastroenterología diagnostica por medio de una serie esófago-gastro-duodenal reflujo gastro esofágico por lo que recibe tratamiento.

Estudios complementarios:

Serie esofagogastroduodenal reporta alteración de la mecánica de la deglución, reflujo gastroesofágico, cambios morfológicos sugestivos de esofagitis y gastritis secundarios y datos sugestivos de mal absorción intestinal.

\section{Estudios de enzimas en sangre seca reporta:} ];

$\alpha$-L-iduronidasa $36.6 \mathrm{pmol} /\left(\right.$ disco $^{*} \mathrm{~h}$ ) [valor de referencia $2.5-15.7 \mathrm{pmol} /\left(\right.$ disco $\left.^{*} \mathrm{~h}\right)$

$\beta$ glucoronidasa de $467.6 \mathrm{pmol} /\left(\right.$ disco*$\left.^{*} \mathrm{~h}\right)$ [ valor de referencia 59.3 - 275.4 $\mathrm{pmol} /\left(\right.$ disco $\left.\left.^{*} \mathrm{~h}\right)\right]$;

$\beta$-galactosidasa de $4.9 \mathrm{pmol} /\left(\right.$ disco*$^{*} \mathrm{~h}$ ) [ valor de referencia de $4.5-11.3 \mathrm{pmol} /$ $($ disco*h)]

aril sulfatasa $\beta$ de $149.6 \mathrm{pmol} /\left(\right.$ disco $^{*} \mathrm{~h}$ ) [ valor de referencia de 7.4 - $23.9 \mathrm{pmol} /$ (disco*h)].

Al estudio anatomopatológico de frotis de sangre se observaron moderada cantidad de linfocitos con abundantes vacuolas con inclusiones azurófilas irregulares, o vacuolas claras, o inclusiones azurófilas gruesas.

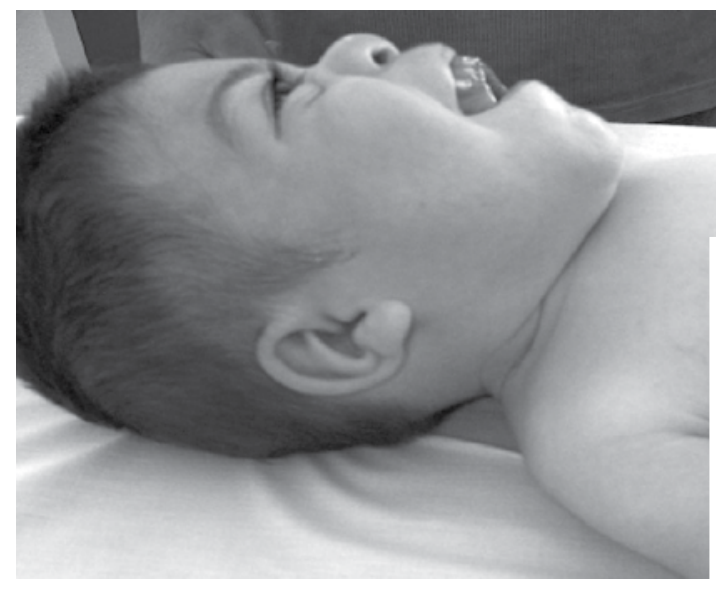

Figura 1. Se observa: puente nasal deprimido, filtrum largo, hiperplasia gingival.

Figura 2. Se observa: teletelia, mano en garra, hernia umbilical.

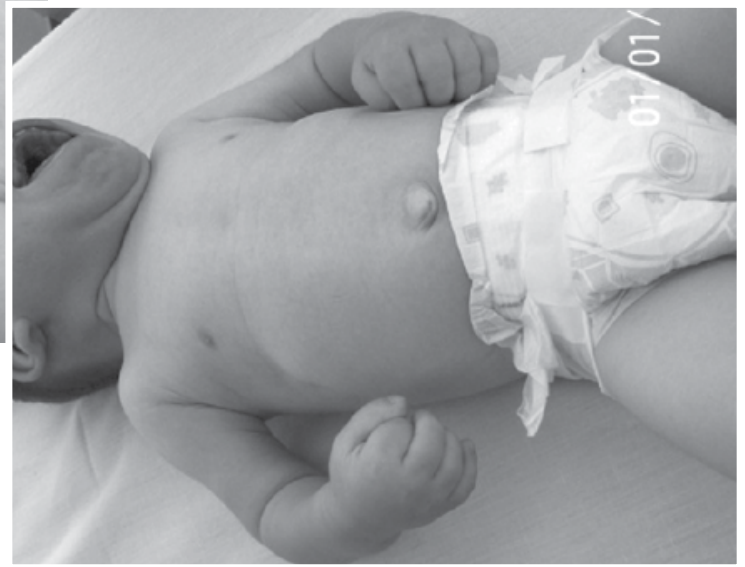




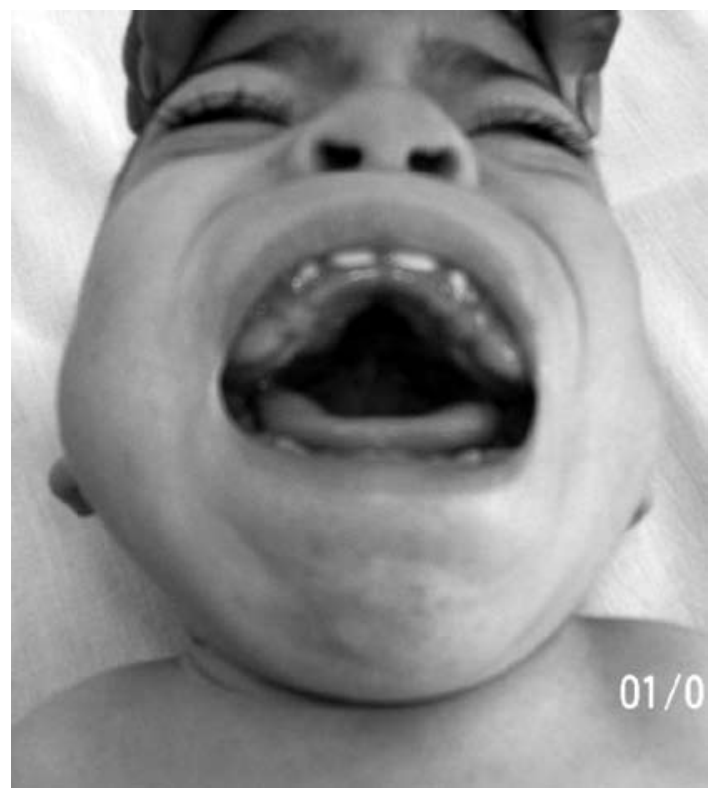

Figura 3. Se aprecia la hiperplasia gingival y el paladar alto.

\section{Discusión}

La enfermedad de células I es una condición hereditaria que clínicamente se asemeja a la enfermedad de Hurler, pero sin la excesiva excreción urinaria de mucopolisacáridos. En contraste con la enfermedad de Hurler, los signos clínicos y radiológicos ya están marcados en la primera infancia con un marcado retraso mental progresivo y muerte por infecciones recurrentes en oídos y en vías respiratorias durante la infancia o la niñez temprana.

El paciente que se presenta, ilustra el cuadro clínico de la enfermedad desde temprana edad y cuyas características fenotípicas son distintivas como: facies tosca, epicanto, depresión del puente nasal, narinas antevertidas, filtrum largo, pabellones auriculares de implantación baja, paladar de arco alto y encías hiperplásicas que nos llevaron a sospechar este diagnóstico.

Típicamente los pacientes presentan un peso al nacimiento menor de 2500 gramos, y es de gran importancia el retardo psicomotor, en un principio su crecimiento es aparentemente normal y que retrocede en su desarrollo alrededor de un año de edad y se detiene casi por completo después de dos años de edad. Debido a su limitado movimiento articular, desarrollan rigidez articular. El paciente presenta un deficiente control de cabeza e hipotonía generalizada. El abdomen es protuberante debido a hernias, hepatomegalia, y las lesiones cardíacas son frecuentes, como la cardiomiopatía hipertrófica progresiva, pero menos importante que en la enfermedad de Hurler. ${ }^{7-9}$. Los soplos sistólicos, cardiomegalia, en particular la ampliación del ventrículo izquierdo demostrado por la radiografía de tórax, la miocardiopatía y las anomalías cardíacas congénitas, tales como dextrocardia y prolapso de la válvula mitral acompañada de prolongación del intervalo QT, son menos frecuentes. La causa de muerte en la primera década de la vida no siempre se determina, pero algunos niños mueren a causa de la insuficiencia cardíaca agravada por neumonías. ${ }^{10}$

La mucolipidosis tipo II se debe a una mutación en el gen GNPTAB, su nombre oficial es $\mathrm{N}$-acetilglucosamina-1 fosfotransferasa, subunidad alfa y beta, pero es conocido con diversos nombres tales como: GlcNAc-1 - fosfotransferasa, GlcNAc fosfotransferasa, GNPTA, GNPTA_HUMAN, entre otros. El gen GNPTAB se encuentra en el brazo largo del cromosoma 12 en la posición 23,2. Más precisamente, en los pares de bases 102.139.274 a 102.224.644 del cromosoma 12 (OMIM 252500, gen locus $12 q 23.2)^{11}$. El gen GNPTAB provee instrucciones para la producción de la enzima llamada G1cNAc-1- fosfotransferasa. Esta enzima está compuesta por subunidades: dos alfa $(\alpha)$, dos beta $(\beta)$ y dos gamma $(\gamma)$. La subunidad gamma está producida en un gen diferente llamado GNPTG, en el cromosoma 16. La G1cNAc-1-fosfotransferasa ayuda a preparar ciertas enzimas recién producidas para el transporte a los lisosomas. Los lisosomas son organelos de la célula, que utilizan enzimas digesti- 
vas llamadas hidrolasas para romper las moléculas grandes en otras más pequeñas para que puedan ser reutilizados por las células. GlcNAc-1-fosfotransferasa está involucrado en el primer paso de la molécula llamada manosa-6-fosfato (M6P). M6P actúa como una etiqueta que indica que una hidrolasa debe ser transportada a los lisosomas. En concreto, GlcNAc-1fosfotransferasa transfiere una molécula llamada GIcNAc-1-fosfato a una hidrolasa de nueva producción. En el siguiente paso, una molécula que se extrae para revelar un M6P unido a la hidrolasa. Una vez que una hidrolasa tiene una etiqueta de M6P, puede ser transportado a un lisosoma. ${ }^{7}$

La Enfermedad de células I se debe diferenciar del síndrome de Hurler, la gangliosidosis generalizada, y las mucolipidosis tipo I y III. A pesar de que existen similitudes fenotípicas entre el síndrome de Hurler y la enfermedad de células I se diferencia por la gruesa piel y por sus valores normales de polisacáridos urinarios, así como los valores de la hidrolasas ácidas tanto en fibroblastos como en los fluidos corporales. La diferencia entre la gangliosidosis generalizada por la actividad normal o baja de galactosidasa en el hígado y finalmente con la enfermedad de mucolipidosis tipo I y III en el grado de afectación física y mental.

El diagnóstico de este paciente se estableció en base al fenotipo característico y se confirmó con los estudios bioquímicos y anatomopatológico (realizados en el Instituto de Hematopatología de México), por la presencia de inclusiones azurófilas en el frotis de sangre, a pesar de que los datos enzimáticos son clásicos de esta enfermedad, la $\beta$-glucuronidasa no está tan elevada como ocurre habitualmente. Se cree que los estudios radiográficos pueden ser de gran utilidad al revelar la presencia de osteopenia grave-severa, las múltiples irregularidades metafisarias y la resorción ósea subperióstica, ${ }^{12}$ sin embargo se requiere de una amplia experiencia así como una capacidad de diferenciación con hiperparatiroidismo, ya que estos datos también son similares a esta enfermedad.

\section{Conclusiones}

El diagnóstico final del paciente fue mucolipidosis tipo II, la cual se sospechó desde un inicio debido a sus características fenotípicas y posteriormente se confirmó demostrando las células con inclusión. A pesar de que la mucolipidosis tipo II es poco frecuente, es importante la detección temprana del síndrome para poder contribuir a un tratamiento adecuado al paciente para mejorar la calidad de vida, así como a los familiares, con un asesoramiento genético adecuado para prevenir el riesgo de recurrencia que es del $25 \%^{13}$. Es indispensable el trabajo de un equipo de especialidades, por lo que debe manejar multidisciplinariamente.

\section{Bibliografía}

1. Grewal S. Shapiro E. Braunlin E. Charnas L. Krivit W. Orchard P. Continued neurocognitive development and prevention of cardiopulmonary complications after successful BMT for I-cell disease: a long-term follow-up report. Bone Marrow Transplantation 2003; 32:957-960.
2. Menéndez I. Menéndez C. Cepero F. Gutiérrez E. Mucolipidosis II. Estudio clínico, bioquímico y genético. Rev Cubana Pediatr 1998; 70(1):53-58.

3. Reitman M. Varki A. Kornfeld S. Fibroblasts from Patients with I-Cell Disease and Pseudo-Hurler Polydystrophy Are Deficient in Uridine 5'-Diphospha- 
te-N-Acetylglucosamine: Glycoprotein N-Acetylglucosaminylphosphotransferase Activity. J. Clin. Invest. 1981; 67: 1574 -1579.

4. Kudo M. Brem M. Canfield W. Mucolipidosis II (ICell Disease) and Mucolipidosis IIIA (Classical Pseudo-Hurler Polydystrophy) Are Caused by Mutations in the GlcNAc-Phosphotransferase a/b-Subunits Precursor Gene. Am. J. Hum. Genet. 2006; 78: 451463.

5. Kolodny E. Mucolipidosis: aspectos clínicos y genéticos. REV NEUROL 1998; 27 (156): 337-341.

6. Madhulika K. SheffaliGulati M. Jyoti S. Arun S. Vikas C. I-cell disease (mucolipidosis II). Indian Journal of Pediatrics, 2000; 67 (9): 683-687.

7. Genetics home reference. Your guide to understanding genetic conditions. (2011); [En línea]. Disponible en: URL: http://ghr.nlm.nih.gov/ condition $=$ mucolipidosis-ii-alpha-beta. Consultado marzo 27 de 2012

8. VanHoof F. Mucopolysaccharidoses and mucolipidoses J. Clin. Path. 1974; 27 (8): 64-93.
9. Kenneth Lyons J. Smith's recognizable patterns of human malformation. 5th ed. E.U.A. W.B. Saunders company, 1997, pág. 452-453.

10. Mazrier H. VanHoeven M. Wang P. et.al. Inheritance, biochemical abnormalities and clinical features of feline mucolipidosis II: the first animal model of human I-cell disease. Journal of Heredity 2003; 94 (5):363-373

11. OMIM. Mucolipidosis II; HFM. USA. (2011); [En línea]. Disponible en: URL: http://omim.org/entry/164210. última actualización: 27 de octubre de 2011. Consultado 19 de junio de 2012.

12. Patriquin H. Kaplan P. Kind H. Giedion A. Neonatal mucolipidosis II (I-cell disease): clinical and radiologic, features in three cases. Am J Roentgenol 1977; 129:37-43.

13. G Leroy J. Cathey, S. Friez, M Mucolipidosis II Synonyms: I-Cell Disease, Inclusion Cell Disease, ML II, Mucolipidosis II Alpha/Beta (ML II Alpha/Beta). GeneReviews. NCBI. 2012 (Internet) [consultado el 25 de junio de 2012). Disponible en: http://www. ncbi.nlm.nih.gov/books/NBK1828/ 